\title{
CRISE ECONÔMICA E RETORNO DOS IMIGRANTES BRASILEIROS EM PORTUGAL
}

Carolina Nunan*

João Peixoto**

\begin{abstract}
A crise econômica internacional desencadeada em 2008 produziu enormes efeitos sobre as migrações mundiais. Alguns estudos têm sido dedicados a esta temática. O objetivo deste artigo é refletir e discutir sobre a existência de um possível fluxo de retorno dos imigrantes brasileiros em Portugal ao país de origem. Os resultados desta investigação apontam para uma desaceleração do fluxo de entrada em Portugal, uma propensão significativa ao retorno, mas um volume efetivo de retorno inferior ao que seria teoricamente de esperar.
\end{abstract}

Palavras-chave: Migração Internacional; Migração Brasileira; Retorno; Portugal; Crise Econômica Internacional.

\section{Introdução}

A crise econômica internacional desencadeada em 2008 produziu enormes efeitos sobre as migrações mundiais. Alguns estudos têm sido dedicados a esta temática. Segundo eles, as alterações verificadas no mapa migratório poderão mesmo anunciar o início de um novo paradigma, com um novo arranjo de regiões atrativas e emissoras e um novo perfil de migrantes internacionais.

Esses estudos indicam que aumentou brutalmente o desemprego entre os imigrantes, por estes normalmente se inserirem nas atividades mais afetadas pela recessão (construção, alojamento e restauração); que o volume dos fluxos migratórios desacelerou fortemente; que os movimentos ligados ao mercado de trabalho, incluindo as migrações temporárias e

\footnotetext{
* Mestre em Tratamento da Informação Espacial (Puc Minas - 2006) e Doutora em Tratamento da Informação Espacial (Puc Minas - 2012). É pesquisadora e professora do MBA da Fundação Dom Cabral e do Centro Universitário Paiva. Belo Horizonte/Brasil.

** Doutor em Sociologia Econômica e das Organizações pelo ISEG-UTL, professor associado do ISEGUTL e investigador no SOCIUS. Lisboa/Portugal.
} 
irregulares, foram os mais afetados; que o volume de remessas abrandou ligeiramente, apesar de revelar uma mais forte resiliência do que outros fluxos financeiros; e que o retorno de imigrantes foi escasso, por o impacto da crise nos países de origem ter sido frequentemente mais intenso do que nos países de destino. A maior exceção a esta situação de baixo retorno parece ter sido verificada em espaços integrados de livre circulação, como a União Europeia, em particular no caso da migração entre a Polônia, Reino Unido e Irlanda. ${ }^{1}$ Além dessas questões, é sempre válido ressaltar o papel fundamental das migrações no equilíbrio das regiões envolvidas e seus impactos na demografia, no contexto sociopolítico e econômico e nas relações sociais.

O objetivo deste artigo é refletir sobre a mudança de posicionamento dos fluxos migratórios entre Brasil e Portugal na sequência da crise e, em particular, discutir a existência de um possível fluxo de retorno dos imigrantes brasileiros em Portugal ao país de origem. Apesar de a evidência de retorno não ser particularmente forte nos estudos efetuados a nível internacional, o volume recente da migração brasileira para Portugal, a multiplicidade das ligações existentes entre os dois países e o grande contraste existente entre as suas situações econômicas atuais sugerem que um movimento significativo de retorno é pelo menos provável. No que diz respeito aos indicadores econômicos, a comparação entre Portugal e Brasil não podia ser mais contrastante: enquanto Portugal foi um dos países da União Europeia mais afetados pela recessão e apresenta sérias dificuldades de recuperação, a economia brasileira demonstra-se pujante no contexto mundial. As consequências deste fato no emprego e no desemprego terão provavelmente consequências nos projetos migratórios.

Uma vez que se trata de uma dinâmica muito recente e que não existem dados estatísticos fiáveis sobre o volume de retorno atual de Portugal para o Brasil, a observação deste tema implica o recurso a diversas fontes. Para a elaboração deste artigo foram assim consideradas metodologias de tipo quantitativo e qualitativo, tendo como técnicas de coleta de dados: análise documental, aplicação de questionário estruturado e entrevistas em profundidade. Mais em pormenor, as técnicas de análise incluíram a análise de dados estatísticos oficiais sobre

\footnotetext{
${ }^{1}$ FIX, Michael et alii. Migration and the Global Recession; MARTIN, Philip. "The recession and migration: alternative scenarios"; KOEHLER, Jobst et alii. Migration and the Economic Crisis in the European Union: Implications for Policy; PAPADEMETRIOU, Demetrios et alii. Migration and Immigrants Two Years after the Financial Collapse: Where Do We Stand?; PAPADEMETRIOU, Demetrios et alii. Migration and the Great Recession: The Transatlantic Experience.
} 
a imigração brasileira em Portugal; indicadores sobre o desemprego e proteção social em Portugal; números do Programa de Retorno Voluntário promovido pela Organização Internacional para as Migrações (OIM); resultados de um inquérito efetuado acerca de 1400 imigrantes brasileiros em Portugal em 2009; e sete entrevistas em profundidade, realizadas nos meses de fevereiro a abril de 2011, com órgãos governamentais e nãogovernamentais em Portugal.

Sobre o inquérito realizado, aconteceu entre Janeiro e Junho de 2009, e foram entrevistados cerca de 1.400 indivíduos adultos de nacionalidade brasileira que residiam ou trabalhavam em todas as regiões de Portugal, inclusive a Madeira e os Açores. O inquérito foi realizado por meio da técnica de amostragem aleatória, tendo muita da sua aplicação ocorrido nas filas dos consulados de Lisboa e Porto. O objetivo deste inquérito foi proceder ao estudo da imigração brasileira em Portugal, através da análise da evolução dos fluxos ao longo do tempo e sua distribuição territorial, as formas de integração e as perspectivas futuras. ${ }^{2}$ O questionário estruturado foi composto por 84 questões, abertas e fechadas, que foram codificadas, tabuladas e analisadas por meio do software SPSS. Para o presente estudo, foram filtrados e apresentados alguns dados relativos à situação e planos futuros dos imigrantes brasileiros.

Quanto às entrevistas, foram realizadas, presencialmente, com representantes da OIM - Organização Internacional para as Migrações; do SEF - Serviço de Estrangeiros e Fronteiras; da ALCC - Associação Lusofonia, Cultura e Cidadania; do Consulado Brasileiro em Lisboa; e da Igreja Evangélica Assembleia de Deus. Tiveram duração média de 60 minutos e foram auxiliadas por um roteiro semiestruturado.

\section{Contexto econômico}

A nível internacional, a crise iniciou-se em 2008 com a falência do tradicional banco norte-americano de investimentos Lehman Brothers, fundado em 1850. Com isso, propagou-se uma onda de recessões pelo mundo, afetando os dois lados do Atlântico. A União Europeia sentiu profundamente seus efeitos. Segundo o Eurostat, a taxa de crescimento real do PIB (Produto Interno Bruto) caiu fortemente entre 2008-2009, apresentando um percentual de apenas $0.5 \%$ em 2008 e um percentual negativo de 4,3\% no último ano. Essa quebra atingiu a grande maioria

\footnotetext{
2 Para mais pormenores, ver GÓIS, Pedro; BAGANHA, Maria Ioannis. "Migrações Internacionais de e para Portugal: o que sabemos e para onde vamos?", p. 229-280.
} 
dos países comunitários, incluindo aqueles cujo crescimento econômico é habitualmente mais forte. Em 2010, porém, o valor médio recuperou, atingindo 1,8\%. Uma das consequências da recessão foi o aumento da taxa de desemprego. Esta, que tinha atingido um mínimo de 7\% para o conjunto dos países da União em 2008, aumentou para 8,9\% em 2009 e $9,6 \%$ em 2010. Nesta conjuntura, sabe-se que o volume dos fluxos imigratórios se reduziu em 6\% no ano de 2008 e o fluxo emigratório cresceu 13\%, de acordo com o boletim do Eurostat divulgado em 2011.

Ao analisar Portugal, o cenário econômico não foi totalmente diferente, apresentando indicadores econômicos e de crescimento em baixa nos últimos anos, em consequência da recessão. Percebese, porém, que a evolução da economia portuguesa possuiu contornos específicos e tem sido mais gravosa do que a média. Assim, a admissão na União Europeia em 1986 e a posterior adesão à moeda única - o euro - transformaram positivamente a economia portuguesa, que se fez visível em sua infraestrutura, em suas cidades. Portugal revigorou-se e teve que se esforçar para aumentar a produtividade de setores tradicionais de sua economia. As fontes de financiamento se multiplicaram e a custos baixos. E, como muitos países em fase de transição, Portugal foi seduzido pelo endividamento. A facilidade com que conseguia financiar défices contribuiu para que Portugal mantivesse uma estrutura de gastos incompatível com seu contexto econômico. Neste cenário, o círculo vicioso se formou, ao apresentar baixo crescimento e alta necessidade de financiamento externo, além de ter se agravado pela crise internacional de 2008/2009, que encontrou Portugal numa situação vulnerável.

Peixoto e lorio $^{3}$ afirmam que em Portugal a situação pré-crise já registrava um maior índice de desempregados nas comunidades imigrantes do que nas populações autóctones, tendo o desequilíbrio conhecido um agravamento como consequência dos impactos da crise. Esse agravamento pode ser considerado como assimétrico, uma vez que os mais expostos são os jovens imigrantes, com ou sem qualificações, e a mão-de-obra masculina adulta sem qualificações, principalmente a situada na construção civil.

Observando a taxa de crescimento do PIB no final da década de 1990, Portugal apresentou um crescimento mais pujante do que a média da União Europeia, chegando a atingir uma taxa de 5\% ao ano em 1998. Porém, o PIB começou a se degradar no início do novo século e, em

\footnotetext{
${ }^{3}$ PEIXOTO, João; IORIO, Juliana. Crise, Imigração e Mercado de Trabalho em Portugal: retorno, regulação ou resistência?
} 
2002, o seu crescimento passou a ser inferior à média da União Europeia. Durante a maior parte da década a economia portuguesa divergiu face à média comunitária. A partir de 2008 a situação agravou-se, atingindo-se um crescimento nulo nessa data e negativo, de -2,5\%, em 2009, ainda assim ligeiramente mais favorável do que a média da União Europeia. Em 2010, apesar de um crescimento ligeiro, a situação de Portugal deteriorouse de novo face aos outros países europeus. Face às dificuldades financeiras do país, está prevista uma nova recessão em 2011 e 2012.

\begin{tabular}{|c|c|}
\hline \multicolumn{2}{|c|}{ Quadro 1 - Desemprego registrado, por profissões (Dez-2010) } \\
\hline 1.1 Quadros superiores da administração pública & 148 \\
\hline 1.2 Diretores de empresa & 6.047 \\
\hline 1.3 Diretores e gerentes de pequenas empresas & 1.384 \\
\hline 2.1 Especialistas ciências físicas, matem. e engenh. & 7.171 \\
\hline 2.2 Especialistas ciências da vida e prof. da saúde & 3.747 \\
\hline 2.3 Docentes ensino secundário, superior e prof. simil. & 3.678 \\
\hline 2.4 Outros especial. profissões intelectuais e científicas & 16.648 \\
\hline 3.1 Técn. nível interm. da física, química e engenh. & 17.875 \\
\hline 3.2 Prof. nível interm. das ciênc. da vida e da saúde & 3.155 \\
\hline 3.3 Profissionais de nível intermédio do ensino & 3.891 \\
\hline 3.4 Outros técnicos e profissionais de nível intermédio & 23.754 \\
\hline 4.1 Empregados de escritório & 55.769 \\
\hline 4.2 Empregados de recepção, caixas, bilheteiras e simil. & 11.794 \\
\hline 5.1 Pessoal dos serviços, de protecção e segurança & 67.772 \\
\hline 5.2 Manequins, vendedores e demonstradores & 39.223 \\
\hline 6.1 Trab. qualificados da agricultura e pesca & 14.297 \\
\hline 6.2 Agricultores e pescadores - subsistência & 187 \\
\hline 7.1 Operários e trab.simil. da ind.extract. e construção civil & 47.150 \\
\hline 7.2 Trab. da metalurgia, metalomecânica e simil. & 21.036 \\
\hline 7.3 Mecânicos de prec., oleiros, vidreiros, artes gráficas & 3.663 \\
\hline 7.4 Outros operários, artífices e trabalhadores similares & 32.486 \\
\hline 8.1 Operadores de instalações fixas e similares & 2.656 \\
\hline 8.2 Operadores máquinas e trabalhadores da montagem & 17.685 \\
\hline 8.3 Condutor de veículos e oper. equip. pesados móveis & 21.332 \\
\hline 9.1 Trab. não qualific. dos serviços e comércio & 69.315 \\
\hline 9.2 Trab. não qualific. da agricultura e pescas & 1.302 \\
\hline 9.3 Trab. não qualific. das minas, construção civil, ind.transf. & 48.675 \\
\hline Total & 541.840 \\
\hline
\end{tabular}

Fonte: IEFP - Instituto 
O desemprego também registou um aumento súbito, passando de um valor de 7,6\% em 2008 para uma taxa de 10,8\% em 2010. O último dado publicado revela uma taxa de 14,8\% em janeiro de 2012. Um dos setores mais afetados pela crise foi o da construção civil, setor em destaque nas ocupações dos imigrantes (ver quadro 1, acima). Por isso, não espanta que a taxa de desemprego dos estrangeiros residentes em Portugal ainda tenha aumentado de forma mais brutal. Em 2010, a taxa de desemprego dos estrangeiros atingia os 18,8\%, e esse valor aumentaria se se considerassem apenas os estrangeiros não comunitários. ${ }^{4}$

Mesmo num cenário de fraco crescimento ou mesmo crescimento negativo, dados indicam que até o final da década houve quase sempre aumento da população estrangeira. As exceções são uma redução de 4\% no ano de 2005 (variação em relação ao ano anterior), mas que se deve sobretudo a alterações da série estatística, e quebras de -0,7\% e -2,6\% em 2008 e 2010, respectivamente, agora já sob o efeito da crise. Em 2010, a população estrangeira reduziu 1,97\%, segundo relatório do SEF (Serviço de Estrangeiros e Fronteiras), porém observa-se um aumento de 2,7\% em relação à comunidade brasileira no mesmo ano.

Por outro lado, é notória a prosperidade brasileira, que apresentou uma taxa média de crescimento anual do PIB de 3,2\% para a última década, aumento de 96\% do PIB per capita a comparar os períodos 1991-2000 e 2001-2009. Em 2010, alcançou um PIB de 7,5\% e em 2011, 2,7\%. Segundo informações divulgadas pelo Banco Central, através do Boletim Anual da Economia Brasileira, o comportamento dos investimentos se constituiu em determinante adicional à sustentabilidade do atual processo de crescimento da economia, em virtude do nível crescente da demanda interna.

Em 2008, o PIB cresceu 5,1\%, colocando o PIB per capita em seu patamar mais alto, correspondente a USD 8.800,00, mantendo a tendência ascendente desde 2000. O Brasil tornou-se conhecido como um dos integrantes dos BRIC's - Brasil, Rússia, Índia e China -, países que se destacaram pelo rápido crescimento de suas economias.

Além desses indicadores, a taxa média de desemprego em janeiro de 2012 foi de 9\%. É de destacar uma redução de 15\% no ano de 2008

${ }^{4}$ Ibidem; PEIXOTO, João. "How the global recession has impacted immigrant employment: the Portuguese case". 
em relação à 2009, auge da crise mundial. Segundo o PNUD (2009), a taxa de desemprego entre os estrangeiros que vivem no Brasil seria de 6,8\% em 2008.

Considerando que o projeto prioritário da maioria dos emigrantes é melhorar sua condição socioeconômica na sociedade de origem, presume-se que uma crise no destino também é fator motivador para a diminuição da emigração e o aumento do retorno. Neste contexto, podese afirmar que os fluxos migratórios Brasil-Portugal foram certamente afetados, principalmente no âmbito do volume, da empregabilidade, das remessas financeiras, da fiscalização pelos órgãos governamentais e do custo de vida. Fatores como desemprego, redução de rendimentos, menor procura por mão-de-obra e maior concorrência, diferenças salariais entre os países envolvidos, maior fiscalização, dentre outros, poderão contribuir para a revisão das expectativas quanto ao retorno. Diante destes indícios, o regresso passa a ser uma realidade viável. Rocha Trindade ${ }^{5}$ corrobora com a ideia, ao afirmar que:

[...] desde o momento em que se cristaliza a intenção de partir, o emigrante é, na generalidade, acompanhado, ao longo de seu itinerário geográfico e temporal, pelo desejo (ou intenção potencial) de regressar um dia ao seu país de origem.

\section{Imigração brasileira}

\subsection{Fluxos de entrada}

Segundo as estatísticas oficiais portuguesas, o aumento do número de cidadãos brasileiros com estatuto legal no país tem sido muito forte: nos anos 1970, o número de brasileiros pouco ultrapassava os três milhares, enquanto em 2010 atingia perto de 120 mil indivíduos. De acordo com estimativas do Ministério de Relações Exteriores do Brasil, o volume é ainda mais elevado: há cerca de 150 mil brasileiros residentes em Portugal, o que faz com que este seja considerado o país mais procurado dentre os pertencentes à União Europeia.

As principais fases de crescimento situaram-se em meados dos anos 1980, no final dos anos 1990 e após meados da primeira década do novo século. O primeiro destes momentos está associado à adesão de Portugal à União Europeia. O segundo e o terceiro momentos estão ligados aos

${ }^{5}$ ROCHA TRINDADE, Maria Beatriz. "Os Reflexos Culturais da Emigração Portuguesa para o Brasil". 
surtos de crescimento econômico então verificados. Os números de brasileiros com estatuto legal refletem, porém, alterações legislativas importantes: o aumento verificado em 2001 resultou da concessão de autorizações de permanência (um título legal que representou, na prática, uma regularização de imigrantes); o crescimento em 2004 e 2005 foi consequência das possibilidades de regularização permitidas pelo acordo bilateral celebrado em 2003 (vulgarmente conhecido por Acordo Lula); e o aumento de 2008 foi resultado das oportunidades de regularização permitidas pela nova lei sobre imigração, em vigor desde $2007 .{ }^{6}$

Uma vez que muitas destas variações resultam de processos de regularização, não é possível conhecer o volume rigoroso de entradas anuais. Os estudos sobre imigração brasileira têm comprovado que muitos dos imigrantes acedem como turistas e passam algum tempo em situação irregular, até se beneficiarem das oportunidades de regularização para obterem um estatuto legal. ${ }^{7}$ Em face desta realidade, podemos admitir que estamos em presença de um fluxo gradual, cuja principal intensificação data do final dos anos 1990. As oscilações têm mais a ver com as alterações legislativas do que com variações reais do fluxo. É possível que um elevado ritmo de entradas se tenha mantido até o final da primeira década do novo século, tendo depois a crise levado à diminuição do fluxo. ${ }^{8}$ Neste sentido, o aumento dos números oficiais a partir de 2008 poderá resultar sobretudo da regularização de entradas anteriores, ou mesmo de processos de obtenção de estatuto legal a anteceder imediatamente o retorno (funcionando o estatuto legal como garantia de regresso à União Europeia caso o projeto de retorno falhe).

Os dados mostram ainda que o Brasil representa a comunidade estrangeira mais expressiva no ano de 2010, com 27\% da população estrangeira, seguida pela comunidade ucraniana e cabo-verdiana, com $11 \%$ e $10 \%$ respectivamente.

Deve ser salientado que o aumento da imigração brasileira é sobretudo relevante porque o fluxo mais intenso ocorreu numa década de reduzido crescimento econômico. Dada a relativamente reduzida expansão do emprego, muitos dos outros fluxos imigratórios para Portugal desaceleraram ou mesmo inverteram a sua tendência. Tal, porém, não

\footnotetext{
${ }^{6}$ A metodologia utilizada para apuração destes números é a contagem do número de autorizações de residência e outros estatutos legais em 31 de dezembro de todo ano.

${ }^{7}$ MALHEIROS, Jorge M. (org.). Imigração Brasileira em Portugal.

${ }^{8}$ PEIXOTO, IORIO, op. cit.
} 
sucedeu com os brasileiros. As dificuldades associadas a outros potenciais destinos (sobretudo no caso dos Estados Unidos), as possibilidades de regularização, a ação das redes sociais e a pressão para a emigração poderão explicar os fluxos, apesar da conjuntura menos expansiva do mercado de trabalho. ${ }^{9}$

As entrevistas realizadas com representantes da OIM, do SEF, da ALCC, do Consulado Brasileiro em Lisboa e da Igreja Evangélica Assembleia de Deus permitiram conhecer melhor a realidade do fluxo de entradas nos últimos anos. Antes de mais nada, a medição rigorosa dos fluxos anuais é problemática. Esta situação foi confirmada pelo representante do SEF, que aponta as relações que envolvem o Espaço Schengen como dificultadoras para apuração dos fluxos, pois prevê livre circulação de bens e pessoas. Portanto, "o quantitativo da comunidade estrangeira é auferido pelo número de Autorizações de Residência mais os vistos próprios,[...] que estão válidos a 31 de dezembro de determinado ano".

Ainda assim, as observações disponíveis indicam a manutenção de alguma pressão para a entrada em Portugal. Ao analisar o Relatório de Imigração, Fronteiras e Asilo (2010), divulgado pelo SEF, houve, em 2010, 50.747 emissões de primeiros títulos de residência, $17 \%$ a menos que no ano anterior (que por sua vez havia registado uma quebra em relação a 2008). Em 2010, os imigrantes brasileiros foram responsáveis por 32\% das concessões, seguidos pelos romenos, com $12 \%$. O representante do SEF afirma sobre o fluxo de entrada:

[...] Até este momento, a comunidade brasileira está em crescimento. Em 2010, é possível que haja um decréscimo do estoque da população estrangeira em Portugal, não necessariamente dos brasileiros. [...] Não é só quem sai. É quem entra e quantos entram. [...] Gente a entrar e a sair, há sempre.

O representante da ALCC compartilha a ideia de que ainda há entrada de brasileiros: "Só que assim, hoje tem 10, amanhã voltam dois e entram dois. Continua o mesmo número. A quantidade que vai embora é muita, mas a quantidade que entra também é igual". E aborda motivos não econômicos como explicação para a permanência do fluxo de entrada, como segurança e reunificação familiar:

\footnotetext{
${ }^{9}$ GÓlS, Pedro et alii. "Segunda ou terceira vaga? As características da imigração brasileira recente em Portugal".
} 
A nível de segurança, aqui oferece mais. [...] Quando temos alguém para partilhar nossos dissabores, é muito mais fácil, vou trabalhar mais tranquila. São três bocas, passam de uma para duas, para três. Mas vou ter mais motivação para ganhar dinheiro. A pessoa feliz, produz.

Perguntado sobre o fluxo de entrada, um dos representantes da OIM cita ainda as possibilidades de regularização da imigração, afirmando que: "Em geral, não houve uma redução... Portugal ainda é atrativo. [...] Ainda há muitos brasileiros a sair do Brasil. Mais do que a entrar. [...] Há um crescimento fortíssimo no Brasil, mas não beneficia a todos ainda".

E complementa essa ideia, ao afirmar que Portugal continua sendo uma opção atrativa e há muita gente a querer sair, segundo contatos que possuem no Brasil:

Muita gente da classe baixa saiu da pobreza, mas aqueles que já eram da classe média e que não encontram empregos satisfatórios ainda pensam em sair do Brasil. O Governo Lula beneficiou mais aqueles que estão na camada baixa, o que é muito bom, mas há muita gente de nível mais alto que não consegue encontrar trabalho.

Poderá ter uma diminuição percentual, mas esta diminuição percentual será sempre, talvez, 3 a 4\%. Não é nada representativo. Por que existe muita gente, de fato, a sair, a regressar aos seus países de origem, mas existe muita gente a entrar. Então, há um equilíbrio.

Perguntados sobre uma possível pressão da fiscalização sobre os imigrantes brasileiros, que poderá diminuir as possibilidades da estada e do trabalho irregular, tanto os representantes do SEF quanto da OIM apontaram que há um investimento na fiscalização dos empregadores, com incidência de maiores coimas, o que poderá restringir o acesso do imigrante irregular ao mercado de trabalho. No entanto, afirmam que não há foco em brasileiros, mas sim em sítios e setores específicos. Segundo o SEF: "A fiscalização segue os seus termos normais".

Uma das razões que tem sido citada para o aumento da imigração em Portugal nos últimos anos são as possibilidades de regularização, incluindo as que foram criadas pela última lei de imigração de 2007. Se essas possibilidades não se ligam a um aumento direto de entradas, pelo menos asseguram que os imigrantes em situação irregular - uma situação endêmica nos países da Europa do Sul - possam alcançar um estatuto 
legal. Outras alterações legislativas têm também permitido uma melhor integração dos imigrantes na sociedade portuguesa.

Sobre as políticas públicas desenvolvidas por Portugal, os entrevistados percebem que a lei de 2007 é bastante favorável, uma vez que simplifica vários aspectos, inclusive o acesso ao mercado de trabalho. Um dos representantes da OIM cita:

É uma lei mais branda. É mais aberta. Ela não prevê uma regularização extraordinária. [...] Mas ela facilita muito para as pessoas que estão aqui já há algum tempo, que estão irregulares, que têm trabalho, rendimentos a regularizar. [...] facilitou muito o reagrupamento familiar. [...] inclusive a lei da nacionalidade, que saiu em 2006, é muito mais fácil do que a antiga.

Também ressalta certa flexibilidade diante do atual contexto:

Agora, também, o SEF facilita um pouco. Normalmente, o SEF exige um rendimento mínimo para poder renovar o visto. Agora, pode ser a metade do rendimento mínimo. Porque tem muita gente nesta crise que perdeu o emprego ou ganha menos. [...] Acho que é justamente para evitar que muitas pessoas saiam.

Já o SEF elogia a legislação portuguesa quanto à possibilidade concreta dada ao imigrante de obter uma situação regular:

... basicamente, só não se regulariza quem não quer ou quem não pode mesmo. Tem pessoas que não podem. [...] As opiniões públicas aceitam muito bem as regularizações. [...] Há muita gente que está a deixar de ser estrangeiro e aceder à cidadania portuguesa.

\subsection{Desemprego e proteção social}

Os números disponíveis sobre desemprego em Portugal, por nacionalidades, confirmam que a recessão econômica afetou de forma mais pronunciada a população estrangeira e, entre esta, os imigrantes brasileiros. Como citado anteriormente, a taxa de desemprego dos estrangeiros atingiu os 18,8\% em 2010, um valor muito mais elevado do que os 10,8\% da população total. Ressalta-se que os setores e ocupações mais atingidas, segundo o IEFP (2010), foram aqueles onde se encontram os estrangeiros: construção civil, comércio e serviços de limpeza, proteção e segurança (rever Quadro 1). 
Os dados relativos aos desempregados inscritos nos Centros de Emprego, por nacionalidades, são também eloquentes a este respeito. O número de brasileiros inscritos nos Centros de Emprego mais do que duplicou entre 2007 e 2009, tendo passado de menos de 5.000 para 10.395 indivíduos em 2009. Em 2010, o valor continua a subir, apresentando 10.529 indivíduos. Os brasileiros foram os mais atingidos entre todas as principais nacionalidades estrangeiras. Em proporção dos desempregados estrangeiros, a tendência foi sempre crescente, atingindo 28,9\% do total em 2010.

Deve-se notar que os dados relativos aos Centros de Emprego referem-se a apenas uma parte dos desempregados totais, porque são sobretudo os desempregados em busca de novo emprego os que aí acedem e porque estão excluídos os imigrantes em situação irregular. Eles são, porém, muito importantes, uma vez que muitos dos desempregados inscritos estão habilitados a receber prestações sociais, em particular o subsídio de desemprego ou o subsídio social de desemprego.

Sobre a eficácia dos Centros de Emprego, o representante da ALCC afirma: "Não funciona pra ninguém. Não é só para imigrante. É pra ninguém". E acrescenta que no mercado de trabalho há preferência pelos nacionais: "[...] vai concorrer a uma vaga e tem 10 brasileiros e um português, o português sempre ganha. Sempre houve uma competição entre brasileiros e portugueses".

Questionada sobre a possibilidade de acreditação da experiência profissional adquirida na origem, o representante da ALCC afirma que depende da ocupação. Mais do que a experiência na função, o que mais se valoriza é o perfil dito "simpático e carinhoso" dos brasileiros:

Aqui, tem que ter o certificado de cabelereiro, manicure e etc. É um trabalho valorizado. As pessoas valorizam o trabalho das brasileiras, mesmo que $70 \%$ não tenha o certificado.[...] Estética é muito valorizado. [...] Outra coisa que é valorizado é o trabalho com os idosos. É extremamente valorizado. A publicidade é muito valorizada. A informática é muito valorizada. [...] Já encontrei psicólogas e pessoas do turismo a trabalharem com idosos. Porque não têm emprego.

Os dados sobre brasileiros que recebem prestações de desemprego confirmam o agravamento recente da sua situação, com a quase duplicação do número de beneficiários entre o início de 2009 e o de 
2010. O máximo foi atingido em Abril de 2010, com quase 8.400 indivíduos, isto é, a maioria daqueles que estavam inscritos nos Centros de Emprego.

Os entrevistados afirmam que o acesso aos subsídios da Segurança Social é um atrativo para a permanência em Portugal: "Pra quem é regularizado [...] tem acesso a qualquer coisa como qualquer cidadão nacional. Tem acesso ao seguro de desemprego, pode se inscrever num Centro de Emprego, num rendimento social mínimo".

Verifica-se, assim, que os imigrantes brasileiros estiveram entre os grupos populacionais mais afetados pela recessão em Portugal. Mesmo se o seu estatuto de residência legal lhes permitiu o acesso a proteção social, em igual condição que os portugueses, as perspetivas para o futuro são incertas. ${ }^{10}$ Os montantes dos subsídios de desemprego são frequentemente baixos, porque muitos dos imigrantes têm uma história contributiva curta; são sempre inferiores aos salários auferidos anteriormente, eles próprios não muito elevados; e as expectativas de regresso ao mercado de trabalho são escassas, dada a fragilidade econômica do país. Neste contexto, não surpreende que o retorno ao Brasil seja encarado como uma hipótese, pelo menos, provável.

\section{Retorno}

\subsection{Intenção de retorno}

O inquérito aos imigrantes brasileiros realizado em 2009 continha uma pergunta sobre os planos futuros. Os resultados indicaram que cerca de $35 \%$ dos que responderam a esta questão afirmaram desejar regressar ao Brasil depois de um certo período. Porém, dentre as diversas respostas dadas, apenas um inquirido citou a crise como possível justificação do regresso. Para além deles, 27,8\% querem permanecer em Portugal, sendo que cerca de um terço destes afirma pretender montar um negócio. Finalmente, 31,5\% confessam a sua indefinição em relação ao futuro.

Inquiridos sobre a duração dos projetos migratórios, a maioria $(35,7 \%)$ apontou o período de dois a cinco anos como o tempo que ainda pretende ficar em Portugal e apenas 5,5\% indicaram querer permanecer por mais de 11 anos. É importante destacar que 26,8\% não souberam responder sobre o tempo de permanência.

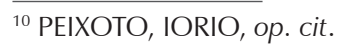


As entrevistas permitiram recolher mais alguns elementos sobre os planos dos migrantes. Sobre a intenção de regresso, o representante da OIM cita que há de fato uma tendência ao fluxo de volta, mas que a decisão de regresso não é uma questão simples. E o representante da ALCC destaca o perfil do retornado como não sendo o mais "pobre":

Os pedidos [de apoio ao retorno voluntário] quadruplicaram desde 2008. Há, de fato, uma tendência de maior retorno. [...] Não é uma consequência direta: crise igual a querer voltar. [...] Pra quem é imigrante, já é tão difícil sair do país de origem. Acho que precisa pensar muito antes de regressar também. [...] As pessoas se agarram de fato ao lugar onde estão, antes de pensar em desistir e regressar ao país de origem. [...] Às vezes tem a vida aqui, tem família aqui. Voltar, às vezes é difícil. O que fazer lá? [...] Eu não acredito em desistência. [...] Não foram os pobrezinhos que voltaram. A crise mundial potencializou o Brasil. E aquelas pessoas que tavam a tentar juntar mais 10 e tinha oito, foi embora. A maioria que voltou, arrumava lá emprego ou tinha situação melhor do que aqui.

E um dos entrevistados ainda confirma a ideia, ao afirmar: "[...] há sempre uma inclinação em ligar o aumento do número de pedidos à uma tendência geral de desistência e não é isso. Tem que se distinguir as coisas".

Ainda sobre esta ideia, o representante do SEF compartilha a opinião da OIM:

É normal que a pessoa faça uma comparação entre as sociedades de origem e destino. [...] Vários fatores pesam. [...] As decisões das pessoas dependem de mais coisas, de afeto, se os pequenos estão a estudar, têm amigos... [...] Há uma infinidade de fatores, que não estritamente o emprego, o econômico, que influenciam as decisões. [...] Eu diria que há retorno, mas é um retorno que tem a ver com o balanço entre a situação das pessoas estarem desempregadas e não terem alternativas e o que elas vão encontrar lá.

O representante da ALCC afirma que nunca se ouviu tanto falar sobre retorno de brasileiros. No entanto, nem sempre esta situação é consequência direta da crise econômica:

Para brasileiro, não há crise. Eu não acredito que tenha havido crise pros brasileiros, porque sempre aprendem 
uma maneira de trabalhar. A crise fez com que muita gente repensasse e voltasse pro Brasil, aqueles que já tinham um pezinho de meia, sim.

Sobre a inexistência de registros sobre os fluxos de regresso, o representante do SEF aponta uma dificuldade em aferir sobre a saída dos residentes:

Esta crise requereria outras fontes que registrem entradas e saídas. [...] Você não sabe por qual motivo as pessoas saem. Portanto, primeiro, não há um registro que se possa utilizar desta medida.[...] Segundo, mesmo que houvesse, como são residentes, não sabe se vão visitar familiares...

E finaliza ao afirmar:

A crise existe e é gravíssima. [...] [Mas] não me parece que foi uma debandada. A minha apreciação não é essa. Não estou a dizer que a imigração não tenha diminuído. Agora, que vamos fugir pois a crise chegou, vamos embora... [...] Portanto, não é uma debandada geral. Mas há mais gente a regressar? Sim. Mas por um conjunto de fatores.

Numa outra opinião, o representante da Igreja Evangélica Assembleia de Deus afirma que os fiéis estão a evacuar as igrejas, o que as deixa em situação econômica crítica, tendo que recorrer àquelas sediadas no Brasil para sua sobrevivência: "Os brasileiros são como aves de arribação. Vão aonde há água".

\section{Considerações Finais}

Os resultados desta investigação são considerados preliminares. Por se tratar de uma dinâmica muito recente, os fluxos e os projetos migratórios são instáveis. A incerteza que reina sobre o futuro econômico de Portugal agrava a situação, pois o desenho dos planos a longo prazo pode ser alterado a qualquer momento. $\mathrm{O}$ fato de não existirem dados estatísticos sobre o regresso condiciona ainda mais a pesquisa. Por isso, o esforço que foi efetuado neste texto foi o de reunir diversas fontes e juntar várias técnicas de análise, de modo a tentar compreender as principais tendências existentes neste campo.

Os resultados a que chegamos indicam uma desaceleração - mas não desaparecimento - do fluxo de entradas. É provável que a maior intensidade da imigração brasileira em Portugal tenha sido atingida por 
volta de 2006, ano no qual os fluxos são intensos e as remessas atingiram o seu valor máximo. A partir daí, o fluxo foi mais reduzido, mas não desapareceu. Alguns dos imigrantes que entraram anteriormente e permaneciam em situação irregular alcançaram um estatuto legal, sobretudo depois de 2007 (nova lei de imigração). Outros foram chegando de novo, seja no âmbito da reunificação familiar ou da manutenção de pressões para a saída no Brasil e alguma procura de trabalho em Portugal.

A recessão econômica afetou, muito fortemente, a comunidade brasileira. O número de desempregados mais do que duplicou nos últimos três anos. Apesar de muitos deles terem acesso ao sistema de proteção social português, recebendo subsídios de desemprego, o escasso montante destes subsídios e a sua duração limitada poderão ser condições não suficientes para manter os planos de residência em Portugal.

Algum retorno vai, assim, tomando forma e tornando-se efetivo. Cerca de um terço dos imigrantes brasileiros planejam regressar (num prazo não determinado) ao Brasil e outro terço afirma-se indefinido. Mas a diminuição das remessas e o forte aumento da procura do Programa de Retorno Voluntário da OIM são sinais de um retorno efetivo. Para além disso, os sinais dispersos de retorno multiplicam-se: muitos dos entrevistados nesta pesquisa disseram conhecer alguém que regressou nos últimos anos.

Em suma, apesar da indefinição, parece certa a existência de algum retorno, mas numa escala ainda moderada e sem anular a existência de algumas entradas. A possibilidade de contínuo agravamento da situação econômica portuguesa e, em paralelo, a manutenção das perspetivas otimistas que rodeiam o Brasil, poderão alterar este cenário no sentido de um incremento do retorno. Por outras palavras, novas pesquisas tornamse necessárias no curto prazo para monitorizar um fluxo tão instável.

\section{Bibliografia}

BANCO Central do Brasil. Disponível em: http://www.bcb.gov.br/pec/boletim/ banual2009/rel2009cap1p.pdf.

BANCO de Portugal. Disponível em: http://www.bportugal.pt/pt-PT/Estatisticas/ Paginas/default.aspx.

IBGE. Instituto Brasileiro de Geografia e Estatística. Disponível em: http://www. bcb.gov.br/?INDECO. 
IEFP. Instituto do Emprego e Formação Profissional. Disponível em: http://www. iefp.pt/estatisticas/MercadoEmprego/EstatisticasMensais/Documents/2010/ Estatística-Mensal-Dezembro10.pdf.

FIX, Michael; PAPADEMETRIOU, Demetrios; BATALOVA, Jeanne et alii. Migration and the Global Recession. Washington: Migration Policy Institute/BBC World Service, 2009.

GÓIS, Pedro; BAGANHA, Maria loannes. "Migrações internacionais de e para Portugal: o que sabemos e para onde vamos?", in Revista Crítica de Ciências Sociais, n. 52/53, p. 229-279, 1999.

GÓıS, Pedro et alii. "Segunda ou terceira vaga? As características da imigração brasileira recente em Portugal", in Revista Migrações - Número Temático Migrações entre Portugal e América Latina, n. 5, 2009, p. 111-133.

KOEHLER, Jobst; LACZKO; Frank, AGHAZARM, Christine et alii. Migration and the Economic Crisis in the European Union: Implications for Policy. Brussels: International Organization for Migration, 2010.

MALHEIROS, Jorge (org.). Imigração Brasileira em Portugal. Lisboa: ACIME, 2007. MARTIN, Philip. "The recession and migration: alternative scenarios". IMI Working Papers, 13, International Migration Institute, University of Oxford, 2009.

MTE. Ministério do Trabalho e Emprego. Perfil Migratório. 2009.

OIM. Relatório Anual de Execução e Avaliação do Programa de Retorno Voluntário 2010. Lisboa: OIM, 2011.

PAPADEMETRIOU, Demetrios; SUMPTION, Madeleine; TERRAZAS, Aaron et alii. Migration and Immigrants Two Years after the Financial Collapse: Where Do We Stand? Washington: Migration Policy Institute/BBC World Service, 2010.

PAPADEMETRIOU, Demetrios; SUMPTION, Madeleine; TERRAZAS, Aaron. Migration and the Great Recession: The Transatlantic Experience. Washington: Migration Policy Institute, 2011.

PEIXOTO, João. "How the global recession has impacted immigrant employment: the Portuguese case", in PAPADEMETRIOU, Demetrios; SUMPTION, Madeleine; TERRAZAS, Aaron. Migration and the Great Recession: The Transatlantic Experience. Washington: Migration Policy Institute, 2011.

PEIXOTO, João; IORIO, Juliana. Crise, Imigração e Mercado de Trabalho em Portugal: retorno, regulação ou resistência? Lisboa: Principia/Fundação Calouste Gulbenkian, 2011.

REYNTJENS, Pascal (ed.). Assessment of Brazilian Migration Patterns and Assisted Voluntary Return Programme from Selected European Member States to Brazil - Research Report (September 2007-February 2009). Bruxelas: International Organization for Migration, 2009. 
ROCHA TRINDADE, Maria Beatriz. "Os Reflexos Culturais da Emigração Portuguesa para o Brasil”, in Análise Social, v. XXII, n. 90, p. 139-156, 1986. SEF - Serviço de Estrangeiros e Fronteiras. Relatório de Imigração, Fronteiras e Asilo 2009 e 2010. Lisboa: SEF. Disponível em http://sefstat.sef.pt/relatorios. aspx.

\section{Abstract}

\section{Economic crisis and return of Brazilian immigrants in Portugal}

The international economic crisis triggered in 2008 produced major effects on global migration. The aim of this paper is to discuss the existence of a possible return flow of Brazilian immigrants in Portugal to the country of origin. The results of this investigation point to a slowdown in the inflows to Portugal, a significant propensity to return, but an actual volume of return smaller than would be theoretically expected.

Keywords: International Migration; Brazilian Migration; Return; Portugal; International Economic Crisis.

Recebido para publicação em 25/03/2012.

Aceito para publicação em 08/05/2012.

Received for publication in March, 25 ${ }^{\text {th }}, 2012$.

Accepted for publication in May, $8^{\text {th }}, 2012$. 